\title{
AVALIAÇÃO DO ESTRESSE, ATRAVÉS DA AVALIAÇÃO DOS PARÂMETROS FISIOLÓGICOS DE UM CÃO SUBMETIDO A ATIVIDADE ASSISTIDA POR ANIMAIS COM IDOSOS
}

\author{
STRESS ASSESSMENT, THROUGH THE EVALUATION OF THE \\ PHYSIOLOGICAL PARAMETERS OF A DOG SUBMITTED TO ACTIVITY \\ ASSISTED BY ANIMALS WITH THE ELDERLY
}

\begin{abstract}
Juliana Nunes Ramos Vaz
Acadêmica do curso de Medicina Veterinária e bolsista do Programa Iniciação Científica pelo Centro Universitário Doctum de Teófilo Otoni - UniDoctum.

E-mail: jununes11@live.com

lanne Rodrigues Cordeiro Acadêmica do curso de Medicina Veterinária e bolsista do Programa Iniciação Científica pelo Centro Universitário Doctum de Teófilo Otoni - UniDoctum.

E-mail: iannecordeiro@hotmail.com

Marcela Gonçalves Cangussu Médica Veterinária

Mestre em Zootecnia-Produção Animal pela Universidade Federal de Minas Gerais. Professora do curso de Medicina Veterinária e orientadora do Programa Iniciação Científica pelo Centro Universitário Doctum de Teófilo Otoni e Professora do curso de Agronomia pela Faculdade Presidente Antônio Carlos de Teófilo Otoni
\end{abstract}

\section{Resumo}

E-mail: mvmarcelacangussu@yahoo.com.br

Atividade Assistida por Animais (AAA) é uma prática direcionada para a melhoria da socialização, permitindo a melhora na qualidade de vida dos idosos através do vínculo com o animal, a partir do toque e do contato, assim propiciando a redução da sensação de solidão, trazendo bem-estar ao animal e ao participante e fazendo com que este último se sinta amado e amparado. A partir dessas considerações, o objetivo do trabalho foi analisar o comportamento do cão-terapeuta e o desenvolvimento de afeição entre o mesmo e os idosos, avaliando dessa forma os parâmetros comportamentais apresentados a cada atividade, bem como avaliando os parâmetros fisiológicos, analisando assim o bem-estar do animal nesse processo. Os resultados observados demonstram que a prática da Atividade Assistida por Animais gera o estreitamento do vínculo afetivo entre um animal e dez idosos, propiciando reflexos positivos nas saúdes física e mental de ambos, sem estresse evidente ao cão nesse processo. Assim, os laços afetivos refletem positivamente no bem-estar do animal.

Palavras-chave: Atividade assistida por animais; Qualidade de vida; Bem-estar; Idosos.

\section{Abstract}


The Animal Assisted Activity (AAA) is a practice aimed at improving socialization, allowing the improvement in the quality of life of the elderly through the bond with the animal, from touch and contact, thus providing a reduction in the feeling of loneliness, bringing well-being to the animal and the participant and making the latter feel loved and supported. Based on these considerations, the objective of the work was to analyze the behavior of the dog-therapist and the development of affection between the dog and the elderly, thus evaluating the behavioral parameters presented to each activity, as well as evaluating the physiological parameters, thus analyzing the animal welfare in this process. The observed results demonstrate that the practice of Animal Assisted Activity generates a narrowing of the affective bond between an animal and ten elderly people, providing positive reflexes in the physical and mental health of both, without evident stress to the dog in this process. Thus, affective bonds reflect positively on the animal's well-being.

Keywords: Animal assisted activity; Quality of life; Well-being; Seniors.

\section{Introdução}

A interação homem-animal remonta aos primórdios da existência de nossa espécie, primeiro com os animais sendo utilizados como suporte às atividades de manutenção à vida e, posteriormente, como animais de estimação, firmando laços de afetividade entre as espécies. (ABRAHÃO et al. 2015)

Sendo assim, a domesticação do animal teve início à partir da criação de um vínculo oriundo dessa interação homem-animal, onde esses animais ganharam um papel mais amplo e significativo dentro da sociedade. Nesse contexto surgiu a visão do animal como auxiliador, a qual se expandiu nos mais diversos âmbitos, inclusive como beneficiador com os cuidados paliativos para a saúde humana, proporcionando a Intervenção Assistida por Animais (IAAs), consiste em prática de intervenção com uso de animais que se subdivide em três modalidades: Terapia Assistida por Animais (TAA), Educação Assistida por Animais (EAA) e Atividade Assistida por Animais (AAA).

A Atividade Assistida por Animais é útil na socialização de pessoas, na psicoterapia, em tratamentos de idosos, pacientes com necessidades especiais, e na diminuição da ansiedade proveniente de várias causas. 
$\mathrm{Na}$ Educação Assistida por Animais o objetivo primordial é promover a aprendizagem, estimulando o desenvolvimento psicomotor e psicossocial em crianças. (ABRAHÃO et al. 2015).

A terapia assistida por animais é uma prática com critérios específicos onde o animal é a parte principal do tratamento, objetivando promover a melhora social, emocional, física e/ou cognitiva de pacientes humanos (MACHADO; ROCHA; SANTOS; PICCININ, 2008).

O contato e a aproximação pessoal com o animal criam a possibilidade de estreitar o vínculo com a equipe de saúde, estabelecendo uma melhor comunicação. Dentre as populações que podem ser atendidas por esse tipo de interação com os animais, encontramos os idosos, em especial os institucionalizados por estarem suscetíveis a sofrerem diversas alterações biopsicossociais, uma vez que o envelhecimento em si traz grandes mudanças no corpo do idoso e estas mudanças, muitas vezes, são difíceis de serem vivenciadas, pois produzem decréscimo funcional em seu organismo, desenvolvendo necessidades de adaptação em diferentes níveis, sejam eles social, psicológico ou físico (MAZO et al., 2005).

Em idosos institucionalizados que, frequentemente, sentem-se isolados e rejeitados pela sociedade, podem ocorrer problemas associados à falta de integração social, facilitando o aparecimento de déficits sensoriais, alterações mentais e aumento da incidência de quadros depressivos. Nestes casos, a TAA tem grande valor e tornase eficiente na redução da solidão, melhorando assim o quadro físico e mental (MAZO et al., 2005) (BANKS, 2002).

Com diferentes intervenções, esse tipo de atividade é utilizado por diversas áreas de atuação profissional do âmbito da saúde (medicina veterinária, fisioterapia, psicologia e assistência social). Esse fato expressa a importância e eficácia da atividade com animais, e da garantia do bem-estar do animal no meio ambiente.

Os cães são os animais mais utilizados para as práticas de TAA devido a sua sociabilidade, fácil adestramento e maior aceitação por parte das pessoas (KOBAYASHI et al., 2009, apud FREITAS et al., 2018).

Por meio dessas características, o objetivo desse trabalho foi analisar o comportamento do cão-terapeuta e o desenvolvimento de afeição entre o mesmo e os 
idosos, avaliando dessa forma os parâmetros comportamentais apresentados a cada atividade e as possíveis alterações fisiológicas oriundas desta, analisando o bemestar do animal nesse processo. Para tanto, foram levadas sempre em consideração as questões bioéticas no desenvolver de toda a atividade assistida por animais, a fim de se estabelecer um respeito entre os envolvidos e alcançar um resultado satisfatório na análise do comportamento do cão.

\section{Atividade Assistida por Animais}

A interação homem-animal data os antepassados da humanidade, onde o animal foi muito utilizado como auxilio no trabalho humano e para o consumo, sendo considerado primordial para o desenvolvimento e evolução da humanidade. Segundo Grandin e Jhonson (2010, apud FISCHER et al., 2016), essa exploração animal só foi possível devido à domesticação, decorrente de alterações genéticas espontâneas promotoras da adaptação ao homem e ao ambiente alterado.

Desse modo, domesticar o animal deu início a criação de um vínculo a partir da interação homem-animal, em que esses animais adquiriram gradualmente um papel muito maior na sociedade. Seu papel como auxiliador se expandiu nos mais diversos âmbitos, inclusive como beneficiador para a saúde humana, proporcionando nesse sentido o início da terapia assistida por animais (TAA).

Os primeiros registros da utilização de animais como beneficiadores da saúde humana ocorreram na Inglaterra, em 1792, quando Willian Tuke fez uso de animais de fazenda com o intuito de analisar os estímulos positivos que deficientes mentais poderiam obter a partir desse contato. $\mathrm{Na}$ época o método era conhecido como tratamento humanizado e, apesar dos resultados satisfatórios, estudos científicos sobre o tema só surgiram anos mais tarde.

No Brasil, a prática foi implementada pela Dra. Nise da Silveira, no hospital psiquiátrico Dom Pedro II, em 1946, no Rio de Janeiro. Mas o marco oficial se deu pela implementação do Projeto Pet Smile, pela psicóloga e veterinária Hannelore Fuchs em 1997, um serviço comunitário filantrópico (FISCHER et al., 2016).

A TAA é definida como um processo terapêutico adotado mundialmente e padronizado pela organização norte americana sem fins lucrativos, Society Delta, a qual desde 1997 fomenta a melhoria na saúde e qualidade de vida humana, através do auxílio dos animais (FERREIRA, 2012, apud FISCHER et al., 2016). Nela, o animal 
é o meio pelo qual o tratamento é realizado, conferindo a terapia o objetivo de promover benefícios e auxiliar na recuperação social, emocional, física e/ou cognitiva de crianças e adultos (MACHADO et al., 2008, apud FERREIRA; GOMES, 2017).

Qualquer tipo de animal que possa entrar em contato com o homem, sem oferecer a ele um perigo controlado, pode ser usado para a terapia, desde que animal seja devidamente treinado. Levando em conta a variabilidade das espécies, a TAA se divide em diferentes modalidades, desenvolvidas de formas diferentes, de acordo com a necessidade de quem a recebe.

Para esse desenvolvimento é necessário o trabalho conjunto de uma equipe multidisciplinar que acompanhe as atividades terapêuticas e garanta o bem-estar dos animais e dos pacientes (ou praticantes, no caso da equoterapia). Outro ponto importante é que o animal seja credenciado, passando por uma série de treinamentos específicos antes de se tornar parte integrante em algum programa de TAA.

$O$ certo é que os animais utilizados sejam isentos de qualquer sofrimento físico ou mental (SINGER, 2004, apud FISCHER et al., 2016), porque eles são seres sencientes que não tem interesse em passar por qualquer tipo de sofrimento.

Ainda há uma escassez de metodologia empírica quando se busca sobre o tema, o que mostra a necessidade de mais pesquisas relacionadas a ele, principalmente com foco no animal. Esses "atores principais" da técnica são totalmente beneficiados ao serem utilizados com fins terapêuticos? Há indícios de estresse nesse método? São questões que geram controvérsias entre diferentes autores, pois os benefícios para os humanos a partir da TAA são variados, como demonstrado em uma análise histórica e social feita por Capote (2009, apud FISCHER et al., 2016). Contudo, se há escassez sobre o tema em geral, são quase nulos os materiais que abordam esse tipo de terapia, com foco nos animais.

O que se sabe é que a TAA faz necessária a existência de um protocolo de implementação, bem como a existência de indicadores analíticos, fisiológicos, patológicos e comportamentais do animal em questão.

A interação homem-animal data os antepassados da humanidade, onde o animal foi muito utilizado como auxilio no trabalho humano e para o consumo, sendo considerado primordial para o desenvolvimento e evolução da humanidade, de acordo com Grandin e Jhonson (2010, apud FISCHER et al., 2016). 
Desse modo, domesticar o animal deu início a criação de um vínculo a partir da interação homem-animal, em que esses animais adquiriram gradualmente um papel muito maior na sociedade. Seu papel como auxiliador se expandiu nos mais diversos âmbitos, inclusive como beneficiador para a saúde humana, proporcionando nesse sentido o início da terapia assistida por animais (TAA).

Os primeiros registros da utilização de animais como beneficiadores da saúde humana ocorreram na Inglaterra, em 1792, quando Willian Tuke fez uso de animais de fazenda com o intuito de analisar os estímulos positivos que deficientes mentais poderiam obter a partir desse contato. Na época, o método era conhecido como tratamento humanizado e, apesar dos resultados satisfatórios, estudos científicos sobre o tema só surgiram anos mais tarde.

No Brasil, a prática com uso de animais foi implementada pela Dra. Nise da Silveira, no hospital psiquiátrico Dom Pedro II, em 1946, no Rio de Janeiro, que utilizava os animais como co-terapeutas no tratamento de pacientes esquizofrênicos, visto que percebeu que os pacientes com dificuldade de contato se vinculavam aos cães com facilidade (BARROS, 2008). Mas o marco oficial se deu pela implementação do Projeto Pet Smile, pela psicóloga e veterinária HanneloreFuchs em 1997, um serviço comunitário filantrópico (FISCHER et al., 2016).

A terapia assistida por animais utiliza várias espécies diferentes para fins terapêuticos, como o cavalo, o cão, o gato, golfinho, pássaros, animais de fazenda (bois, vacas, galinhas) e animais silvestres (furões, hamsters e tartarugas). A terapia assistida por cães (TAC) é a modalidade mais utilizada nas visitas em escolas e asilos, fazendo uso do cão como terapeuta.

Ela teve sua origem no século XVIII, na Inglaterra, quando foi descoberto que o convívio com cães trazia benefícios psicológicos, pedagógicos e sociais ao seu praticante. (OLIVEIRA, 2007, apud FISCHER et al., 2016). E foram estabelecidos como base para seu uso, a motivação, sensibilidade, concentração e socialização, tanto do animal quanto do paciente.

Estudos comprovam os benefícios de um cão na vida do ser humano; o simples ato de acariciar o animal é capaz de reduzir a pressão arterial, liberando o hormônio do relaxamento, a serotonina, e diminuindo o hormônio do estresse, o cortisol (SOUSA, 2016). E, segundo Odendaal (2000, apud FISCHER et al., 2016), benefícios 
também podem ser identificados no cão, sendo eles: aumento de endorfina, ocitocina, prolactina, ácido fenilacético e a diminuição do cortisol e da pressão sanguínea.

\subsubsection{A utilização do cão nas Intervenções Assistidas por Animais em idosos}

A benéfica interação dos animais com os seres humanos vem sendo construída desde a antiguidade, seja por fins de produção ou simplesmente companhia (DOTTI, 2005). Assim, nascem os conceitos da Terapia Assistida por Animais (TAA), que se constitui da utilização de animais com finalidades terapêuticas, visando promover principalmente a saúde física, e da Atividade Assistida por Animais (AAA), que apresenta objetivos de visitação, recreação e distração por meio do contato com os animais (DOTTI, 2005).

O contato e a aproximação pessoal com o animal criam a possibilidade de estreitar o vínculo com a equipe de saúde, estabelecendo uma melhor comunicação. Dentre as populações que podem ser atendidas por esse tipo de interação com os animais, encontramos os idosos, em especial os institucionalizados por estarem suscetíveis a sofrerem diversas alterações biopsicossociais. $\mathrm{O}$ envelhecimento traz grandes mudanças no corpo do idoso e estas mudanças, muitas vezes, são difíceis de serem vivenciadas, pois produzem decréscimo funcional em seu organismo, desenvolvendo necessidades de adaptação em diferentes níveis, sejam eles social, psicológico ou físico (MAZO et al., 2005).

Em idosos institucionalizados que, frequentemente, sentem-se isolados e rejeitados pela sociedade, podem ocorrer problemas associados à falta de integração social, facilitando o aparecimento de déficits sensoriais, alterações mentais e aumento da incidência de quadros depressivos. Nestes casos, a TAA tem grande valor e tornase eficiente na redução da solidão, melhorando assim o quadro físico e mental (MAZO et al., 2005) (BANKS, 2002).

Por sua vez, esses tipos de IAA's, como a Atividade Assistida por Animais, podem se relacionar com diversas áreas, como por exemplo, o desenvolvimento psicomotor, desenvolvimento sensorial, emocional e na recuperação da autoestima de idosos em asilos, através de recreações de atividades baseadas no vínculo idosoanimal. Assim o animal vai proporcionar momentos de motivação e incentivo 
aos idosos nas realizações das atividades, melhorando a sua psicomotricidade, afetividade e, consequentemente, a qualidade de vida.

\subsection{O papel do médico veterinário durante Atividade Assistida por Animais.}

O papel do médico veterinário dentro das terapias é de muita importância, pois, além de cuidar do bem-estar do animal e da saúde física/mental dos animais, ele deve estar sempre atento nas questões de saúde pública. O médico veterinário que deseja seguir esse âmbito precisa estar preparado para atuar em uma equipe multidisciplinar de saúde.

Segundo Flôres (2009), o médico veterinário é responsável também pela avaliação dos animais, sendo o único profissional capacitado para verificar a saúde do animal terapeuta. O veterinário tem a função de orientar, informando os cuidados básicos de saúde e higiene do animal, como as suas particularidades. Ele também deve participar do desenvolvimento do projeto, realizando avaliações frequentes do comportamento do animal e estabelecendo esquemas de cuidados higiênicosanitários e calendários de vacinação e vermifugação.

A Organização Mundial de Saúde reconhece a importância dos animais como zooterapeutas, por isso se preocupa com a plena saúde física deles. Neste contexto, é reforçado o papel essencial do Médico Veterinário no sentido de acompanhar as manifestações comportamentais do animal, bem como zelar pela sua saúde garantindo que não haverá risco de transmissão de zoonoses e contaminação do local de realização da terapia (ANDERLINE e ANDERLINE, 2007).

Portanto, é importante que o médico veterinário conheça todos os tipos de terapias, uma vez que ele é único profissional capaz de assegurar e ter conhecimento especializado sobre o animal terapeuta, aliando saúde, comportamento e o bem-estar animal, além da estimulação da interação animal-paciente.

\section{Metodologia}


As visitas foram realizadas com um grupo de 10 idosos, de ambos os sexos, nos quartos e no espaço aberto existente numa instituição de longa permanência, as visitas eram feitas semanalmente, no período da tarde sempre respeitando a rotina do local. O cão utilizado, previamente socializado, foi acompanhado por uma médica veterinária, um fisioterapeuta e alunos de graduação dos cursos de medicina veterinária e fisioterapia.

A partir da parceria com a fisioterapia, houve a realização de atividades motoras com os idosos, onde o cão foi contribuinte através dos exercícios que faziam. Durante os exercícios realizados, os idosos foram estimulados a caminhar com o cão, a jogar a bola para o alto com uma mão ou as duas e, para aqueles que possuíam deficiência motora, houve a realização da atividade de jogar a bola para o cão pegar.

O cão-terapeuta Zeus reside em ambiente domiciliar, se relacionando com os integrantes da família e outros animais (cão e gatos). Sua rotina inclui passeios semanais, descanso em variadas horas do dia, interações com todos os residentes da casa, alimentação balanceada e visitas regulares ao médico veterinário, apresentando sua carteira de vacinação em dia. Mais além, obteve um treinamento prévio antes da socialização com os idosos.

Ao longo das atividades, o comportamento do cão foi avaliado em dois tempos distintos: antes da atividade, quando o cão ainda se apresentava em casa, ou seja, no seu ambiente familiar, e durante a realização das atividades. A partir dessa diferenciação, foi observada a forma como o animal se comportava em cada um desses momentos, com base nos padrões pré-estabelecidos (calmo, alerta, agressivo e medo) no artigo. Assim, as avaliações oriundas permitiram ressaltar o comportamento predominante, chegando à análise final de cada dia de realização da atividade.

Os padrões de comportamento, foco de avaliação da pesquisa, foram então baseados em características físicas específicas que o animal poderia expressar, como determinado na ficha de avaliação comportamental, para essa posterior análise ser realizada.

Para a avaliação das possíveis alterações fisiológicas, houve também a divisão da coleta em dois tempos diferentes: antes do início da AAA, no local de realização desta, logo depois da chegada do cão; e após a realização das atividades. A observação 
então se baseou na existência dos parâmetros fisiológicos requeridos (temperatura retal, frequência cardíaca e frequência respiratória) nos dois momentos, propiciando uma comparação entre eles a afim de se possibilitar uma mensuração acerca da existência de estresse para o cão, devido as atividades.

Para tanto, a aferição dos parâmetros foi feita da seguinte maneira: a pulsação foi aferida com mão na artéria femoral por 15 segundos, para a obtenção da frequência cardíaca, sendo que houveram coletas em que um estetoscópio foi utilizado para auscultação dessa pulsação; os movimentos respiratórios foram aferidos através da observação da movimentação da caixa torácica por 15 segundos, para obtenção da frequência respiratória. Nesses dois casos, o valor obtido foi multiplicado por quatro, a fim de se determinar tais frequências no intervalo de um minuto. Por sua vez, a temperatura retal foi aferida com um termômetro digital, o qual foi introduzido no reto do animal com o uso de vaselina.

Assim, as alterações fisiológicas foram baseadas em possíveis variações dos padrões de temperatura, frequência cardíaca e respiratória, como determinado na ficha de avaliação fisiológica, para a realização de posterior análise dos dados obtidos, ao fim de todas as coletas. Sendo que foram realizadas 12 coletas durante três meses, as quais uma média de duração de 45 minutos.

\section{Análise de dados}

Sabendo que a sociabilidade, o fácil adestramento e a maior aceitação por parte das pessoas são características que tornam o cão um animal ideal para a terapia de modo geral, todos esses fatores foram observados de modo notável na interação do cão terapeuta utilizado, Zeus, de três anos, da raça ShihTuz, e os idosos participantes da atividade assistida por animais.

Após o período de socialização, no qual ele foi apresentado aos idosos distribuídos em um círculo, sendo assim estimulado o contato com o cão através do toque. Nas posteriores visitas o cão terapeuta demonstrou reconhecimento ao local da atividade, bem como aos idosos, vindo a criar um vínculo afetivo com estes. Tal fato é demonstrado pela forma de agir do cão durante os momentos no recanto, se 
mostrando amigável e alegre, o que foi expresso pelo rabo abanando ao reconhecer as pessoas e interagir com elas.

Durante as coletas realizadas, o animal demonstrou medo não acompanhado de agressividade, exteriorizado pelo comportamento de permanecer abaixado, com a cauda entre as pernas e as orelhas pendulares. Todavia, tal comportamento ocorreu apenas em curtos momentos, menos de um minuto cronometrado, em que o cão interagiu com pessoas não usuais na atividade.

Levando tal ponto em consideração, o desconforto passou após o contato inicial com as pessoas desconhecidas e o animal voltou a apresentar-se calmo, seu comportamento predominante em cada dia de realização da atividade, bem como em sua região domiciliar. Essa predominância é mostrada no gráfico abaixo, considerando as coletas dos parâmetros comportamentais.

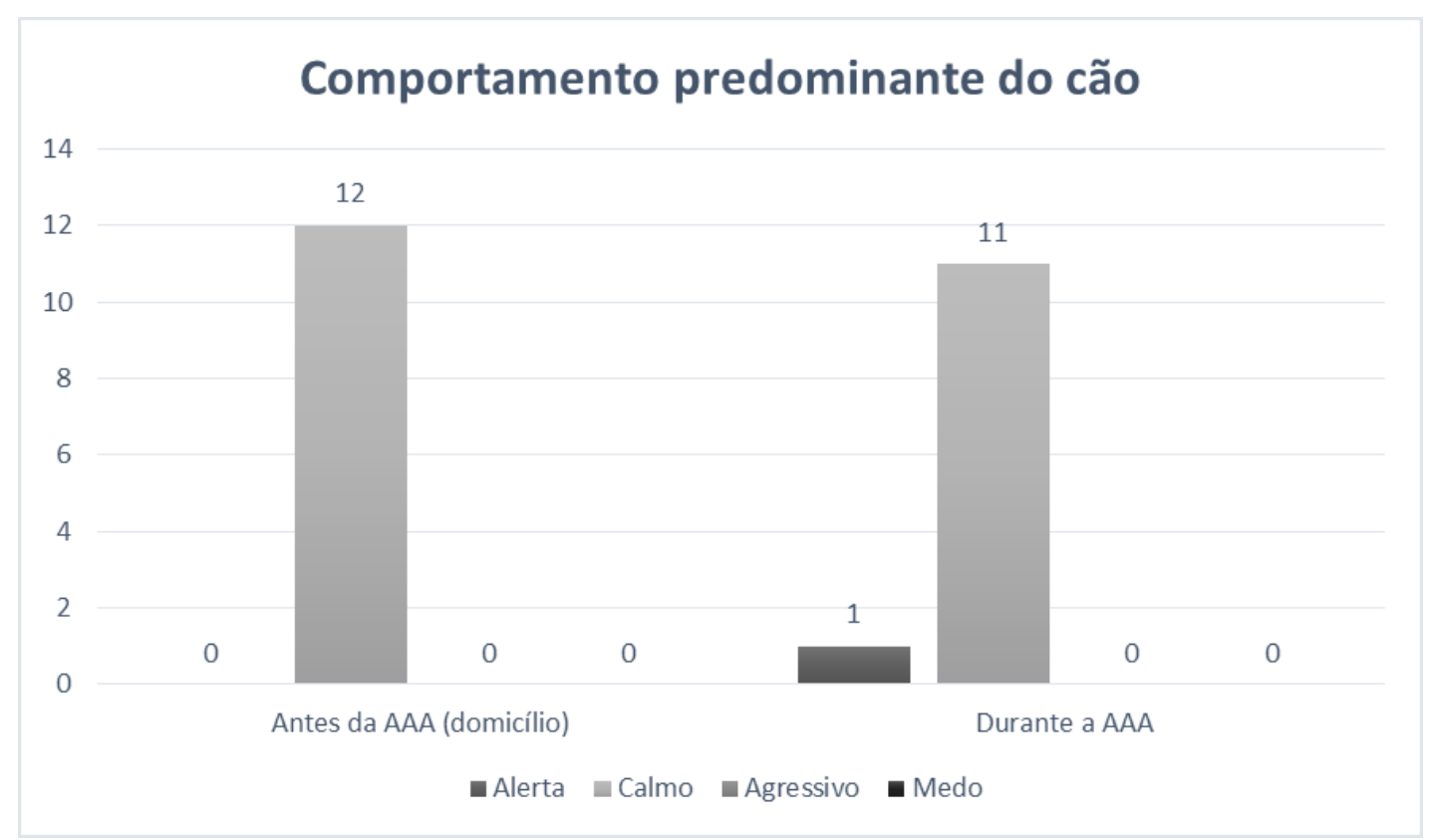

Figura 1. Gráfico com os parâmetros comportamentais predominantes antes e depois da AAA.

Citando que essa predominância de comportamento foi diferente apenas no primeiro dia da Atividade Assistida por Animais, onde o ShihTzu passou pela socialização com os idosos e reconhecimento do ambiente novo para ele. Nesse dia, 
o cão se mostrou mais alerta ao ambiente ao seu redor. Em todo caso, a partir da avaliação comportamental não foi possível realizar uma correlação com possíveis sinais de estresse, como apontado por Yamamoto et al. (2012).

Com relação aos aspectos fisiológicos, observando-se os valores da frequência cardíaca (FC) foi notável que houve um considerável aumento desta após a realização da atividade assistida por animais, quando o cão realizava todos os exercícios propostos. Em contrapartida, nos dias em que esses exercícios não podiam ser realizados, devido a imprevistos ocorridos, e o cão passava um maior tempo interagindo no colo dos idosos, nos quartos, essa frequência cardíaca tendia a ser menor ao ser aferida após a atividade do que no momento em que se chegava ao recanto.

Esse fato pode estar atribuído a excitação do animal ao ser transportado até o local, seguida da maior quietude durante a atividade nesses momentos específicos, a qual acabava exigindo um esforço mínimo do mesmo.

Entretanto, independentemente da situação, os valores obtidos permaneceram dentro dos parâmetros considerados normais (60 - 160bpm-batimentos por minuto) para o animal, como representado no gráfico abaixo:

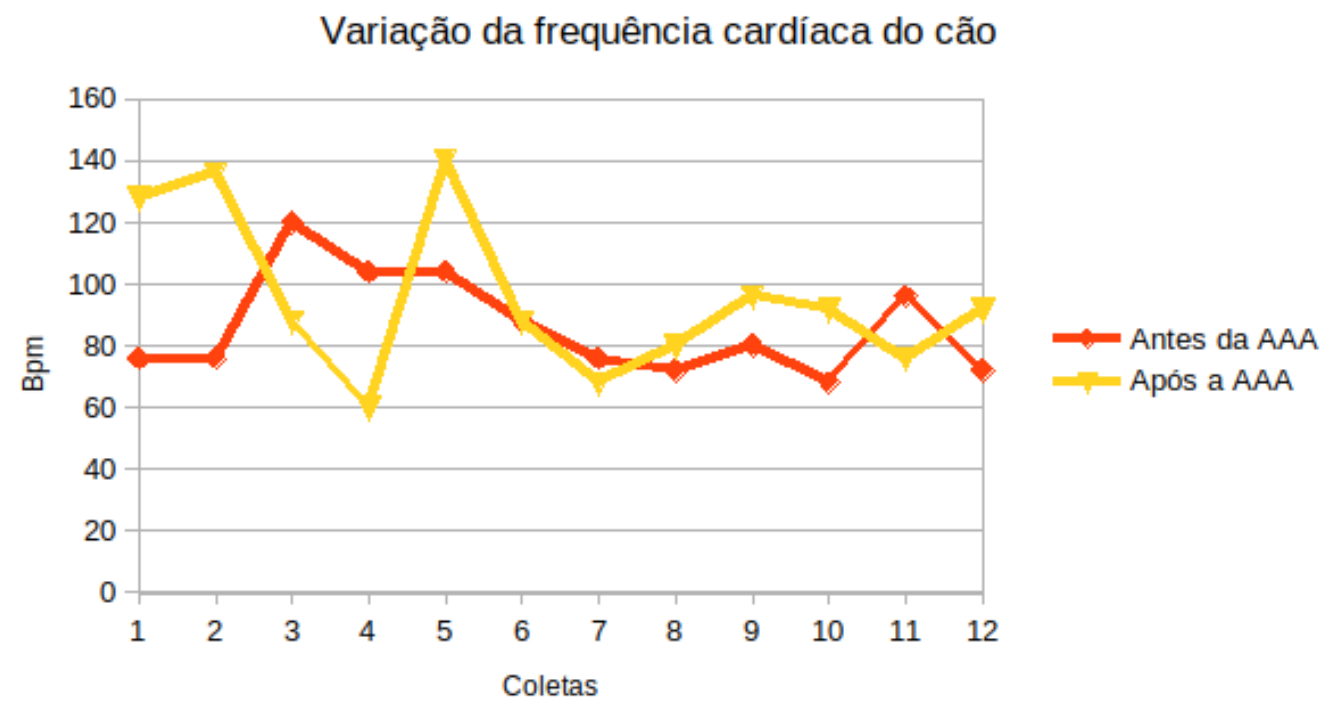

Figura 2. Gráfico da frequência cardíacaantes e após a realização da AAA. 
Por outro lado, os valores da frequência respiratória (FR) foram evidentemente discrepantes dos parâmetros normais para o animal (18 - 36mpm-movimentos por minuto), estando muito acima do esperado tanto antes da realização da atividade, quanto depois. Assim como na frequência cardíaca esse aumento foi ainda mais perceptível nos dias em que o cão realizou todos os exercícios propostos. Outro fator que interferiu nesses resultados, foi a forma em que o cão foi transportado para o local da atividade e como se deu a sua manipulação. Além do fato de ser um animal braquiocefálico, apresentando movimentos respiratórios mais frequentes que outras raças.

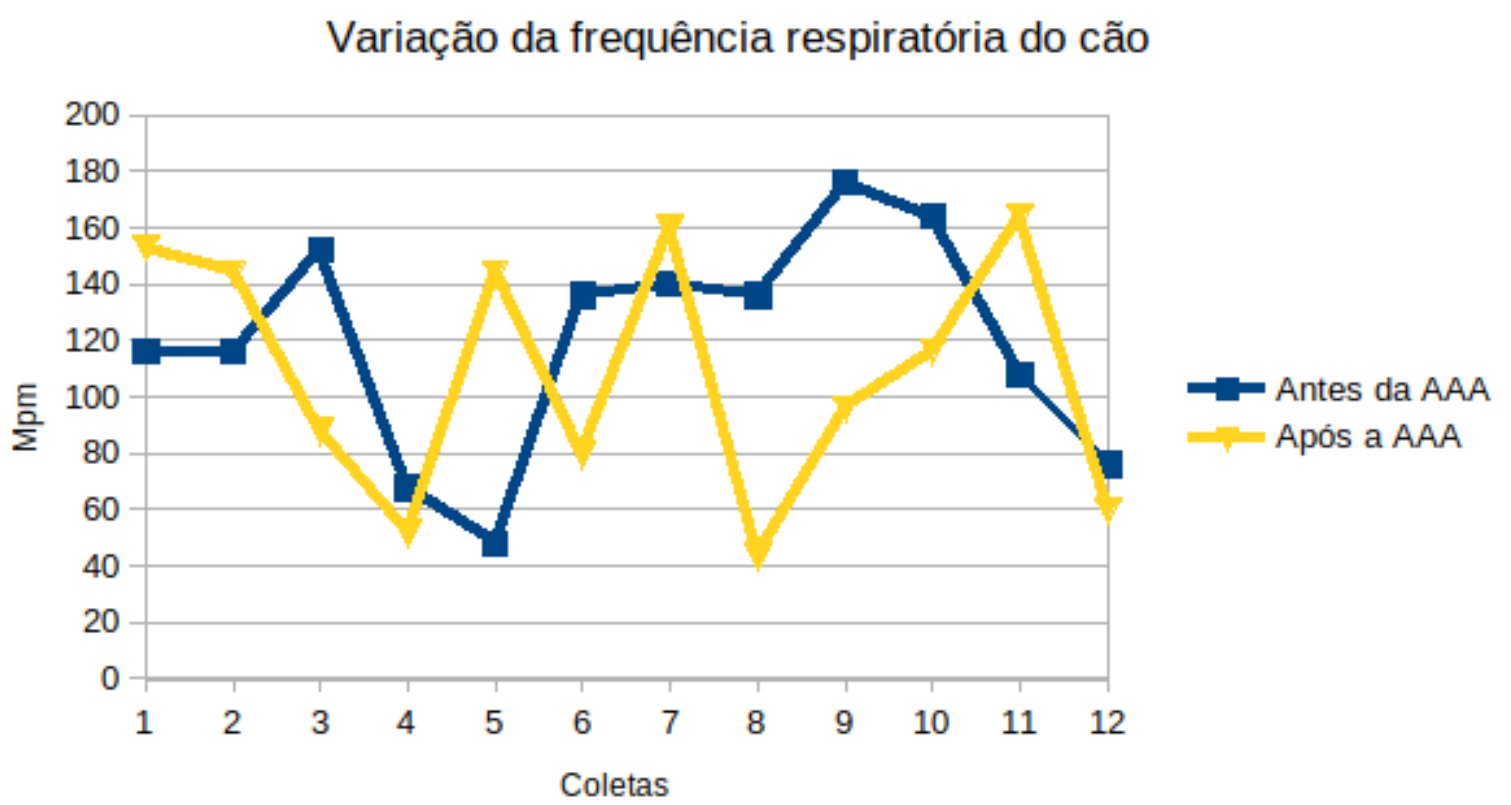

Figura 3. Gráfico da frequência respiratória antes e após a realização da AAA.

Ao ser levado andando para o recanto em alguns dias, houve um aumento mais significativo da frequência respiratória antes da atividade, do que nos dias em que o cão foi para o local em um veículo.

A temperatura real (TR) na maioria das aferições se mostrou dentro dos parâmetros normais $\left(37,5-39,2^{\circ} \mathrm{C}\right)$, se mostrando levemente mais acentuada em apenas duas coletas, em momentos diferentes. 


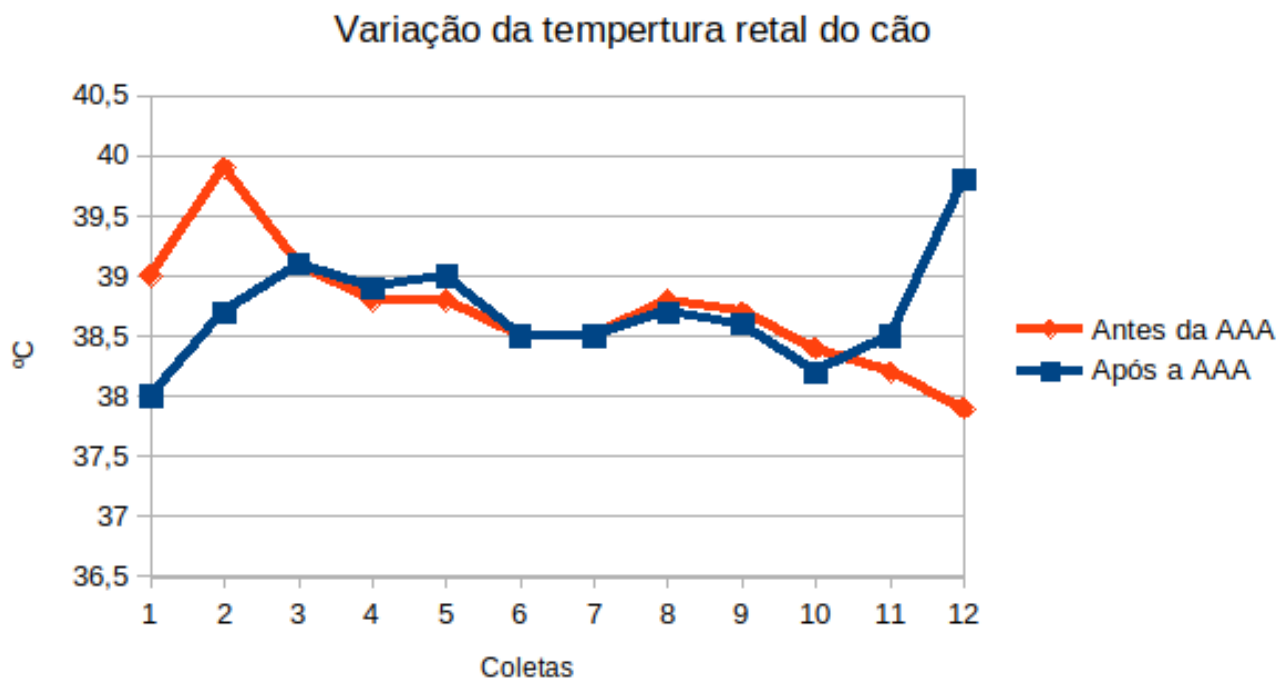

Figura 4. Gráfico da temperatura retal antes e após a realização da AAA.

Foi visível a melhora na maioria dos idosos diante da presença do cão, apresentando-se mais motivados, contentes e com melhor aceitação para realização de atividades cotidianas como sair do quarto para o refeitório e tomar banho.

A interação do animal com os idosos, propiciou com que essas pessoas demonstrassem melhorias evolutivas e por vezes sutis, no decorrer das visitas, como o sorriso presente no rosto de muitos deles e o desejo de levantarem da cama ao verem o cão-terapeuta Zeus. Durante esses momentos, também pôde ser observado, que o cão se mostrou mais afeiçoado a alguns idosos de forma específica. Demonstrando a capacidade do desenvolvimento do comportamento homem animal por essa espécie.

Outra melhoria fora das condições motoras dos membros superiores de uma das idosas ao jogar a bola para cão-terapeuta, apresentando mais desenvoltura nesse exercício após alguns dias da atividade. Ela também demonstrou um grande afeto ao ver o animal a cada visita, existindo uma significativa reciprocidade por parte do cão.

Houve também uma melhoria no estímulo da memória de outra idosa, no reconhecimento facial e noção de espaço. Além disso, foi observado que uma outra participante da atividade assistida por animais, que inicialmente não queria ter contato com o cão, passou a apresentar, com o tempo, um carinho enorme pelo animal, 
reivindicando constantemente que colocasse Zeus no seu colo para que ela pudesse afagá-lo.

Observando os padrões de comportamento apresentados pelo animal antes da atividade e durante a mesma, nota-se que sinais indicativos de medo ou agressividade, demonstrados por Zeus, foram mínimos (medo) ou inexistentes (agressividade). O cão se manteve calmo durante esses momentos, de modo quase linear, com sinais de alerta ocasionais, não necessariamente provocados pelo contato com os idosos, mas pelo ambiente externo.

Esse fator implica não haver estresse na AAA para o cão, com base nos quatro comportamentos utilizados (calmo, alerta, medo, agressividade), definidos por expressões sociais padronizadas e observadas a cada atividade. Ainda que esse resultado seja um ponto mais subjetivo.

Compactuando com essa conclusão acerca da relação entre o comportamento e o estresse do animal durante a AAA, os parâmetros fisiológicos ressaltam o fato de que a atividade não causa estresse negativo no cão, pois não houve cronicidade, apenas estresse agudo ocasional em determinadas situações, o que é necessário ao animal no funcionamento adequado de sua fisiologia.

Acentuando ainda que a frequência respiratória aumentada não se relaciona com a frequência cardíaca, estando supostamente associada a raça e alterações de temperatura, como a ocorrência de dias mais quentes, os quais essa FR se elevava. Outro fator que inferiu nas oscilações dos parâmetros fisiológicos foi a mudança de ambiente, de um espaço aberto para um reduzido (quartos), o que limitou o comportamento natural do animal devido essa redução, interferindo assim nos valores dos parâmetros.

Em todo caso, o comportamento do cão foi satisfatório e o seu bem-estar preservado nas práticas, baseando-se em ambos os parâmetros, com benefícios, como a demonstração de alegria e afeto, gerados ao mesmo pelo claro vínculo construído com os participantes durante todo o processo. 


\section{Conclusão}

Os resultados obtidos mostram que existe uma melhoria significativa na execução das atividades motoras por parte dos idosos. Esse fato se traduz em um impacto positivo na qualidade de vida dos idosos participantes da AAA, propiciando assim benefícios, tanto para o animal quanto para o idoso, uma vez que não houve alterações significativas no comportamento do cão terapeuta, que poderiam ser prejudiciais ao mesmo.

O comportamento apresentado durante cada atividade, demonstra que os possíveis sinais de estresse não possuem relevância e que o animal interagia com os idosos mostrando entusiasmo, o que se traduz em uma situação benéfica a ambas as partes. Os parâmetros fisiológicos também se mantiveram dentro do valor esperado, sem consideráveis oscilações, salvo para a frequência respiratória. Apesar desses valores serem elevados, supõe-se que isso pode estar relacionado a raça do animal, não necessariamente devido a situações de estresse.

Dessa forma, a atividade assistida por animais aparenta não causar, portanto, estresse significativo no cão, segundo os parâmetros comportamentais e fisiológicos avaliados. Assim, a atividade assistida por animais mostrou que a afeição dos idosos com o animal e deste com os idosos, foi perceptível a cada semana, o que acentua a importância das visitas. Além do mais, foi possível observar que para o sucesso da AAA é necessária uma integração entre todos os envolvidos, para se respeitar o espaço, o tempo, e garantir a efetividade dos benefícios oriundos ao cão e aos idosos.

\section{Referências}

ABRAHÃO, F.; CARVALHO. M.C. Educação assistida por animais como recurso pedagógico na educação regular e especial-uma revisão bibliográfica. Revista Científica Digital da FAETEC - Rio de Janeiro/RJ. V.8. № 01.2015

CAETANO, E. C. S. As contribuições da TAA- terapia assistida por animais à psicologia. Tese para obtenção do título de Trabalho de Conclusão de Curso. Universidade do Extremo Sul Catarinense. Criciúma. 2010

CARVALHO, F. D., et al. Uso da atividade assistida por animais na melhora da qualidade de vida de idosos institucionalizados. 2011.p. 149-150.

CARVALHO, I. A., et al. Terapia assistida por animais: Teoria e Prática. Caratinga-MG: FUNEC Editora, 2018. 
SILVA, E. Y. T., et al. Incremento da saúde e da qualidade de vida de idosos institucionalizados através da convivência com animais de companhia e atividade assistida por animais (AAA). Rev. Ciênc. Ext. v.5, n.2, p.84-85, 2009.

SILVA, M. P., et al. Terapia Assistida por Animais: Cinoterapia, Equoterapia, Delfinoterapia e Ronronterapia. XI SEZUS-Semana acadêmica do curso de zootecnia. Universidade Estadual de Goiás. Agosto-2017.

OLIVEIRA, G. R.; CUNHA, M. C. Efeitos da Atividade Assistida por Animais nas condutas comunicativas de idosos: abordagem fonoaudiológica. Rev.

DistúrbComun, São Paulo, 29(4): 644-653, dezembro, 2017

SOUSA, N. K. L. Terapia facilitada por cães: Estudo de caso. Tese de trabalho de conclusão de curso no Centro de Ciências Agrárias da Universidade Federal da Paraíba, para obtenção do título de Bacharel em Zootecnia. Areia-PB. 2016.

STUMM, K. E. Utilizando a terapia assistida por animais para idosos. Terapia assistida por animais: Teoria e Prática. Caratinga-MG: FUNEC Editora. p.173-186. 2018.

SALOMAO, P. E. A. et al. As Tecnologias de Informação e Comunicação (TIC) no ensino superior. Revista Multidisciplinar do Nordeste Mineiro, v. 1, 2018.

ZAMO, R. SOUZA.: MARINHO, J. R. S. Terapia assistida por animais e transtornos do neurodesenvolvimento. Estud. pesqui. psicol., Rio de Janeiro, v. 17, n. 3, p. 1063-1083, 2017.

YAMAMOTO, K. C. M., et al. Avaliação fisiológica e comportamental de cães utilizados em terapia assistida por animais (TAA). Arq. Bras. Med. Vet. Zootec., v.64, n.3, p.568-576, 2012 